\title{
LA DESIGUALDAD DE TRATO EN LA TRIBUTACIÓN DE LAS SUCESIONES Y DONACIONES EN ESPAÑA Y LA UNIÓN EUROPEA
}

\section{UNEQUAL TREATMENT IN THE TAXATION OF THE INHERITANCE AND GIFT IN SPAIN AND THE EUROPEAN UNION}

\author{
EVA MARÍA SÁNCHEZ SÁNCHEZ ${ }^{1}$
}

\begin{abstract}
Sumario: I. INTRODUCCIÓN. II. HISTORIA Y CARACTERÍSTICAS DEL IMPUESTO SOBRE SUCESIONES Y DONACIONES. III. DESIGUALDAD DE TRATO FISCAL EN EL IMPUESTO SOBRE SUCESIONES Y DONACIONES DENTRO Y FUERA DEL TERRITORIO NACIONAL PROVOCADA POR EL EJERCICIO COMPETENCIAL DE LAS COMUNIDADES AUTÓNOMAS. IV. LAS FUNCIONES DE LA RESIDENCIA FISCAL EN EL DERECHO DE LA UNIÓN EUROPEA. V. DICTAMEN DE LA SENTENCIA DEL TRIBUNAL DE JUSTICIA DE LA UNIÓN EUROPEA, DE 3 DE SEPTIEMBRE DE 2014 (ASUNTO C-127/12), COMISIÓN EUROPEA CONTRA REINO DE ESPAÑA. VI. MODIFICACIÓN DE LA LEY 29/1987, DE 18 DE DICIEMBRE, DEL IMPUESTO SOBRE SUCESIONES Y DONACIONES, NUEVA REDACCIÓN A SU DISPOSICIÓN ADICIONAL SEGUNDA, DADA POR LA DISPOSICIÓN FINAL TERCERA DE LA LEY 24/2014, DE 27 DE NOVIEMBRE. VII. EL DERECHO Y PROTECCIÓN A LA PROPIEDAD PRIVADA Y A LA HERENCIA EN EL CONTEXTO COMUNITARIO ACTUAL. VIII. RECIENTE PRONUNCIAMIENTO DEL CONSTITUCIONAL CONTRA LA DISCRIMINACIÓN TERRITORIAL POR MOTIVO DE RESIDENCIA EN SUCESIONES. IX. CONCLUSIONES.
\end{abstract}

\begin{abstract}
Summary: I. INTRODUCTION. II. HISTORY AND CHARACTERISTICS OF THE INHERITANCE AND GIFT TAX. III. UNEQUAL TAX TREATMENT IN THE INHERITANCE TAX WITHIN AND OUTSIDE THE NATIONAL TERRITORY CAUSED BY THE EXERCISE OF COMPETENCES OF THE AUTONOMOUS COMMUNITIES. IV. THE FUNCTIONS OF THE FISCAL RESIDENCE IN THE EUROPEAN UNION LAW. V. DiCTUM OF THE JUDGMENT OF THE COURT OF JUSTICE OF THE EUROPEAN UNION, OF 3 SEPTEMBER 2014 (CASE C-127/12), EUROPEAN COMMISSION VS. KINGDOM OF SPAIN. VI. MODIFICATION OF THE LAW 28/1987, OF 18 DECEMBER, ON THE GIFT AND INHERITANCE TAX, NEW REDACTION AT ITS SECOND ADDITIONAL DECREE, GIVEN BY THE THIRD FINAL DECREE OF THE LAW 24/2014, OF 27 NOVEMBER. VII. THE RIGHT AND PROTECTION TO PRIVATE PROPERTY AND INHERITANCE IN THE CURRENT COMMUNITY CONTEXT. VIII. RECENT DECISION OF THE CONSTITUTIONAL COURT AGAINST TERRITORIAL DISCRIMINATION ON THE GROUNDS OF RESIDENCE IN SUCCESSIONS. IX. CONCLUSIONS.
\end{abstract}

Resumen: Una de las materias que más disputas ha provocado recientemente sobre el Derecho tributario ha sido la disparidad de medidas normativas adquiridas por las Comunidades Autónomas en el Impuesto sobre Sucesiones y Donaciones. Esta diversidad de preceptos provoca a nivel interno desigualdad de trato fiscal entre los ciudadanos españoles, pero además, plantea problemas de compatibilidad con las libertades Comunitarias. La articulación de toda estructura normativa en beneficio de la justicia tributaria que debe inspirar cualquier medida en la imposición de los tributos,

\footnotetext{
${ }^{1}$ Doctora en Derecho Financiero y Tributario, sobresaliente “cum laude”, por la Universidad de Jaén.
} 
debe estar presidida por los principios constitucionales del art. 31.1 de la Constitución española de 1978, que constituyen el fundamento del sistema tributario y la unidad del sistema, donde debe destacar por su correspondencia con ellos, el principio de igualdad tributaria. La contemplación desde la proyección tributaria del derecho de propiedad privada, constituye la disciplina constitucional en el contexto europeo de armonización fiscal y protección de confiscatoriedad.

Palabras clave: igualdad, Comunidades Autónomas, Impuesto sobre Sucesiones y Donaciones; Unión Europea.

Abstract: One of the themes that most recently provoked disputes over tax law has been the disparity of normative measures acquired by the Autonomous Communities in inheritance and gift tax. This diversity of precepts at internal level causes unequal tax treatment among Spanish citizens, but also raises problems of compatibility with Community liberties. The articulation of the entire normative structure for the benefit of tax justice that should inspire any measure in imposing taxes, must be presided by the constitutional principles of article 31.1 C.E. that constitute the foundation of the tax system and the unity of the system, in which must stand out for its correspondence with them, the principle of tax equity. The contemplation from the tax projection of the right of private property forms a part of the constitutional discipline in the European context of tax harmonization and protection of the confiscation.

Keywords: equality, Autonomous Communities; Inheritance and gift tax; European Union.

\section{INTRODUCCIÓN}

El Impuesto de Sucesiones resulta un clásico dentro del repertorio tributario, referido a las herencias, que en su aplicación actual se ha expuesto a desigualdades, exclusiones y perjuicios comparativos injustos, adoptando diferentes tratos fiscales. Este carácter de injusticia, está vulnerando el principio de igualdad de tal modo que puede ser merecedor de ser expulsado de la esfera constitucional.

Recordemos que el impuesto realiza ciertamente una valiosa misión de inspección en las transmisiones del patrimonio, al proporcionar información trascendente para la gestión y control de los mismos, así como de los rendimientos y rentas que se derivan de ellos. No obstante, al estar configurado como un tributo cedido parcialmente por el Estado a las Comunidades Autónomas, respecto de la rentabilidad que el impuesto produce en el territorio de cada una de ellas, el ejercicio de las funciones de gestión llevado a cabo por las mismas haya traído en la actualidad la controversia sobre el mantenimiento o supresión del impuesto, especialmente cuando las rentas proceden esencialmente de las clases de naturaleza media, produciendo importantes desigualdades para los ciudadanos que deben pagar el tributo en distintos espacios territoriales destinados a ello. 
Desde que se iniciara el proceso de descentralización financiera de los entes autonómicos, diseñados por el art. 137 de la Constitución española de 1978, en lo referido a la participación de los ingresos en materia impositiva, que devenía en beneficio del principio de suficiencia financiera, en los últimos años ha sufrido una gran elevación. La reforma de 1997 sobre financiación autonómica² reforzó el principio de corresponsabilidad de forma que hoy las Comunidades Autónomas tienen capacidad y poder para realizar decisiones normativas que establezcan algunas de las cláusulas para su recaudación, lo que les ha permitido mayor competencia sobre la obligación del Impuesto sobre Sucesiones y Donaciones.

Como consecuencia de la presencia de diversas normativas en la tributación para el Impuesto de Sucesiones y Donaciones, se ha favorecido la ejecución de considerables diferencias, quedado expuesta en función de la residencia. Esta individualidad de las Comunidades para realizar la gestión de este impuesto, hace irrealizable cualquier propósito de unificación, lo que conlleva una desigualdad impositiva perjudicial para los más sencillos contribuyentes.

Ello pone de manifiesto que el fundamento del debate si la financiación autonómica pone en riesgo principios constitucionales tributarios del art. 31.1 de la Constitución española de $1978^{3}$, cabe considerar que el respeto a la igualdad y no discriminación se ven claramente desprotegidos al consentir a las Comunidades Autónomas obrar de una manera determinada ante la normativa de impuestos estatales y causar distinciones tributarias por motivo del territorio. En cualquier caso, corresponde al Estado velar por la igualdad de los ciudadanos en todo su espacio, a través de los instrumentos fiscales que sean necesarios para asegurar el cumplimiento del deber de contribuir de acuerdo con los mandatos de la Constitución.

\section{HISTORIA Y CARACTERÍSTICAS DEL IMPUESTO SOBRE SUCESIONES $Y$ DONACIONES}

\section{Historia}

La creación del Impuesto de Sucesiones y Donaciones en el sistema tributario español parece venir de lejos, pues ya se hallaba en la época romana imperial. En nuestra historia más reciente, para algunos tendría lugar en la llamada manda pía forzosa que fue un tributo establecido por las Cortes de Cádiz en España y sus colonias

\footnotetext{
${ }^{2}$ El nuevo modelo de financiación de las Comunidades Autónomas aplicable al quinquenio 1997-2000, estuvo inspirado en el principio de corresponsabilidad fiscal, y fue materializado por la Ley Orgánica 3/1996, de 27 de diciembre, de financiación de las Comunidades Autónomas.

${ }^{3}$ Principios paralelamente con una problemática europea. Vid. LÓPEZ ESPADAFOR, C.M., "Il ruolo della definizione dei principi materiali di giustizia tributaria nell'integrazione fiscale europea”, en Diritto e practica tributaria, vol. 85, parte I, n. 6/2014, p. 997.
} 
en la primera parte del siglo XIX, para satisfacer y socorrer a los damnificados por la guerra de la independencia y, se recaudaba en forma de legado forzoso sobre los testamentos y sucesiones intestadas ${ }^{4}$. Otros han entendido, que su construcción vino dada con la reforma tributaria de 1900 donde el Impuesto sobre Sucesiones y Donaciones quedaría englobado en el Impuesto sobre Derechos Reales, junto con las transmisiones onerosas inter vivos, quedando uno y otro identificados conjuntamente.

La separación de ambos tributos llegó con la reforma del 11 de junio de 1964 por entender que estos tributos tienen distintos gravámenes. Por un lado, la tributación del Impuesto sobre Sucesiones y Donaciones que grava los beneficios de las transmisiones mortis causa, tiene por objeto el rendimiento patrimonial de quien logra los bienes y derechos de forma beneficiosa y, por otro el de Transmisiones Patrimoniales gravosas inter vivos que se basa en la capacidad económica que se obtiene con la transmisión de la misma.

Aunque el Impuesto sobre Sucesiones y Donaciones se conforma como un tributo sobre aportaciones hereditarias que incide sobre las personas físicas, se trata esencialmente de dos hechos imponibles diferentes, como son sucesiones y donaciones y, está considerado una sola figura impositiva que incorpora tanto las transmisiones a título ganancioso, mortis causa para la sucesión, como inter vivos en el caso de la donación, permaneciendo regularizadas en un mismo texto normativo. De esta forma, dentro del Impuesto sobre Sucesiones y Donaciones existen dos amplias ramificaciones con una ordenación disímil pero conectada, y cuyo nexo está en la naturaleza a título gratuito de la adquisición que obtiene el sujeto pasivo (si el carácter de la transmisión fuera gravoso, sería de aplicación el Impuesto sobre Transmisiones Patrimoniales). Esta reforma llevó también consigo, la desaparición del caudal relicto que se requería como exacción suplementaria.

Su historia más inmediata tiene su importancia en la reforma fiscal introducida con la llegada de la democracia a nuestro país, donde el vigente Impuesto General sobre las Sucesiones de 1967, fue sustituido por el actual Impuesto sobre Sucesiones y Donaciones establecido por la Ley 29/1987, de 18 de diciembre ${ }^{5}$. Esta nueva norma, introdujo elementos novedosos en la configuración del impuesto, dejando fuera del mismo las adquisiciones lucrativas a favor de personas jurídicas incorporándolas al Impuesto de Sociedades para su tributación. La estructura de esta Ley de 1987, aunque ha sufrido varias modificaciones, se mantiene vigente en la actualidad y, supone la fuente más significativa en la regulación del ISD. Además, existen las normas de las Comunidades Autónomas que regulan las materias de sus competencias referentes a este impuesto.

\footnotetext{
${ }^{4}$ CANGA ARGÜELLES, J., Diccionario de Hacienda con aplicación a España, Fabrica Nacional de Moneda y Timbre, $2^{\mathrm{a}}$ ed., Tomo II, Madrid, 1968, p. 74.

${ }^{5}$ La Ley 29/1987, de 18 de diciembre, del Impuesto sobre Sucesiones y Donaciones, fue desarrollada por el RD 1629/1991, de 8 de noviembre.
} 


\section{Características}

Nos encontramos ante un Impuesto que destaca por su carácter directo y subjetivo, que a su vez, grava en exclusiva los incrementos patrimoniales adquiridos de manera beneficiosa por las personas físicas, en los límites previstos en la Ley ${ }^{6}$. El Impuesto de Sucesiones y Donaciones cierra el cuadro impositivo directo español.

Aunque se trata de un impuesto con dos hechos imponibles distintos en base a sucesiones y donaciones, puede considerarse como una sola figura impositiva que acoge las transmisiones patrimoniales de manera gratuita por mortis causa para la sucesión, e inter vivos para la donación. Este carácter gratuito que tiene la adquisición por parte del sujeto pasivo, sirve como nexo para la relación de las dos ramificaciones existentes en el mismo.

El Impuesto de Sucesiones y Donaciones es un impuesto directo, por recaer sobre una manifestación de enriquecimiento de patrimonio de forma inminente que incrementa la capacidad económica del sujeto por la adquisición de bienes gratuitos ${ }^{7}$, también, porque responde a un método impositivo de naturaleza directa constituido por la Ley, al ordenar que la obligación de pago se realice directamente por el obligado tributario, sin otorgar derecho legal a que otra persona pueda resarcirlo.

Igualmente, es un impuesto subjetivo porque se tiene en consideración las particularidades personales de los sujetos ${ }^{8}$, como es el vínculo familiar entre beneficiario y causante, minusvalía, edad, y cualquier otra circunstancia que afecte a la modulación en el cómputo de la deuda tributaria, como es el patrimonio del que disponía el sujeto pasivo antes de ese momento. Esa subjetividad viene dada por la exclusividad del impuesto a la hora de limitar el gravamen a las personas físicas ${ }^{9}$. De ahí, que se considere personal por estar relacionado con un individuo determinado. Junto a estas características apuntadas, se puede defender además su carácter particular instantáneo, individual, progresivo y jurídico ${ }^{10}$.

\footnotetext{
${ }^{6}$ El impuesto sobre Sucesiones y Donaciones viene regulado fundamentalmente por la Ley 29/1987, de 18 de diciembre. Desarrollado en el Real Decreto 1629/1991, de 8 de noviembre. Tiene por objeto, la adquisición de bienes y derechos recibidos a través de herencia u otro título sucesorio; la adquisición de bienes y derechos a consecuencia de una donación, así como también por otro negocio jurídico gratuito e inter vivos; o la captación de cantidades por los beneficiarios de contratos de seguros de vida, siempre que el contratante figure como persona diferente del beneficiario.

7 BENÍTEZ DE LUGO Y GUILLÉN, F., El Impuesto sobre las Sucesiones y sobre las Donaciones, Comares, Granada, 1992, p. 66.

${ }^{8}$ BALLESTER GINER, E., Derecho de sucesiones, Aspecto civil y fiscal, Editoriales de Derecho Reunidas, Edersa, 2a ed., Madrid, 1989, p. 279.

${ }^{9}$ CALVO ORTEGA, R., La fiscalidad de las Sucesiones y las Donaciones, Lex Nova, $2^{\mathrm{a}}$ ed., Valladolid, 1991, p. 315. Señalando que la subjetividad cobra más importancia en las adquisiciones por donación a título gratuito e inter vivos.

${ }^{10}$ CAAMAÑO ANIDO, M.A. y PEÑA ALONSO, J.L., El Impuesto sobre Sucesiones y Donaciones, Editoriales de Derecho Reunidas, Edersa, Madrid, 2002, pp. 27-30.
} 
Siendo de gran trascendencia para las sucesiones mortis causa, que el patrimonio del difunto no sea acumulado por todas las adquisiciones recibidas por la familia ${ }^{11}$. Estas cualidades determinan los rasgos de su progresividad, dado que, conforme va aumentando el patrimonio del beneficiario, de igual forma se acrecienta la base liquidable $\mathrm{y}$, por consiguiente, la deuda tributaria, a efectos, de ofrecer una mejor repartición de la carga tributaria y acentuar la función social que persiguen todos los impuestos, desapareciendo con ello, las reglas que llevaban a una desigualdad en el repartimiento de la obligación. Pero ha sido sin duda, la implantación de una tarifa única del impuesto, la que ha modelado mejoras significativas en el procedimiento tributario para conseguir una importante progresividad en cuanto al fondo liquidable.

Finalmente, hay que destacar que nos hallamos ante la figura de un impuesto especialmente jurídico, en orden a la obligación de que la regulación y liquidación tributaria de los contratos de actos o negocios efectuados por sucesión o donación, se tornarán respetando la identidad legal de la adquisición efectuada. Este mandato, autoriza a la Administración para fijar la naturaleza jurídica, conforme a la legislación aplicable.

Por último, el Impuesto de Sucesiones y Donaciones se constituye como un tributo designado a las Comunidades Autónomas, dándoles capacidad para ordenar deducciones de la cuota imponible, así como la regulación de la tarifa, pero no para hacerlo desaparecer. Es el Estado quien configura su fundamento básico y su existencia, y por tanto, debe velar porque todos los españoles seamos iguales ante la ley. Si bien, es sabido que la igualdad en materia tributaria está intrínsecamente comunicada con el principio constitucional de capacidad económica que suponen los elementos fundamentales para establecer el Impuesto sobre Sucesiones y Donaciones, donde deberá preservarse la singularidad y autonomía de las personas físicas respecto a la obligación individual de los sujetos ante este tributo y en base a su suficiencia, lo que repercutirá en justicia e igualdad, dado que, por exigencia de la justicia e igualdad tributaria se requiere idéntico trato, cuando se halle ante dos posiciones iguales, para que su retribución sea la misma. A la actuación de las competencias ante el Impuesto de Sucesiones y Donaciones, brindaremos el título siguiente.

III. El EJERCICIO COMPETENCIAL DE LAS COMUNIDAdES AutónOMAS PROVOCA DESIGUALDAD DE TRATO FISCAL EN EL IMPUESTO SOBRE SUCESIONES Y DONACIONES DENTRO Y FUERA DEL TERRITORIO NACIONAL

\section{La problemática situación actual en España}

\footnotetext{
${ }^{11}$ PÉREZ-FADÓN MARTÍNEZ, J.J., Guía del impuesto sobre Sucesiones y Donaciones, CISS, $3^{\mathrm{a}}$ ed., Valencia, 2006, p. 24.
} 
El Impuesto sobre Sucesiones y Donaciones (ISD) se encuentra inmerso en nuestro presente sistema impositivo y posee titularidad estatal, motivo por el cual, solo podrá ser pretendido, modificado o suprimido por el Estado. Sin embargo, su condición de cedido ${ }^{12}$ establece que las Comunidades Autónomas posean poderosas capacidades normativas sobre su reglamentación, que han devenido en importantes diferencias en el gravamen de este indicador de manifestación de la capacidad económica de los contribuyentes. Es decir, los tributos cedidos ante la proyección impositiva autonómica, se caracterizan por la diversidad normativa ${ }^{13}$. Esta disparidad de procedimientos ha llevado a resurgir las polémicas alrededor de la obligación y conveniencia de la imposición sobre las sucesiones, e incluso de si es justo ${ }^{14}$.

La intensa proliferación de disposiciones autonómicas que repercuten en el Impuesto deja en evidencia el diferente trato que reciben los contribuyentes dentro del territorio español a la hora de pagar sus impuestos ${ }^{15}$. Todo ello, como consecuencia de la aplicación del criterio de conexión en la aplicación del régimen jurídico de este tributo en las diferentes Comunidades Autónomas, creando enormes diferencias en la carga fiscal del sujeto en aplicación de donde casos el causante tuviese la residencia, de la dirección de los inmuebles cedidos y en otros, por la ubicación de la residencia del que los adquiere. Estas desigualdades por razón de residencia obedecen a la aplicación del punto de conexión estipulado, que en las adquisiciones mortis causa será en el territorio de la Comunidad donde el causante tuviese su residencia habitual. En las donaciones beneficiosas inter-vivos dependerá de la naturaleza del bien transmitido, y cuando se trate de bienes inmuebles será la Comunidad Autónoma donde éstos se hallen, mientras que para los demás bienes y derechos, será en el lugar donde el receptor tenga su residencia habitual ${ }^{16}$.

\footnotetext{
12 La Ley 22/2009, de 18 de diciembre, por la que se regula el sistema de financiación de las Comunidades Autónomas de régimen común y Ciudades con Estatuto de Autonomía y se modifican determinadas normas tributarias, establece en su artículo 25.1.c que el Impuesto sobre Sucesiones y Donaciones se inserta como tributo del Estado cedido a las Comunidades Autónomas, al menos explícitamente. Además de la cesión de la totalidad del rendimiento generado en su territorio (art. 32) tienen además atribuidas amplias capacidades en materia normativa. Así se observa en su art. 48 de esta norma, al disponer que las Comunidades Autónomas ostentaran las competencias normativas siguientes:

1. Reducciones de la base imponible.

2. Tarifa progresiva del gravamen.

3. La fijación de cuantías y coeficientes del patrimonio preexistente.

4. Bonificaciones y deducciones sobre la cuota.

5. También se les habilita para regular los aspectos de gestión y liquidación del impuesto.

13 LORENZO-REGO entiende que el "contribuye a la redistribución de la riqueza por detraer un porcentaje de cada adquisición lucrativa en favor del Tesoro Público” (El concepto de familia en Derecho español, Un estudio interdisciplinar, Bosch Editor, $1^{\text {a }}$ ed., Barcelona, 2014, p. 261).

${ }^{14}$ GARCÍA DE PABLOS, J.F., "El Impuesto sobre Sucesiones y Donaciones, Supresión o reforma”, Crónica Tributaria, n. 139/2011, p. 79.

${ }^{15}$ BARBERÁN LAHUERTA, M.A., "Presente y futuro del Impuesto sobre Sucesiones y Donaciones", Cuadernos de Información económica, n. 173/2003, pp. 73 y 75.

${ }^{16}$ VILLARÍN LAGOS, M., La cesión de impuestos estatales a las Comunidades Autónomas, Lex Nova, Valladolid, 2000, pp. 250 y 251.
} 
Este horizonte hace pensar que determinadas Comunidades Autónomas se hayan beneficiado de mayor recepción de donaciones de inmuebles por dejarlos realmente eximidos de tributación del ISD $^{17}$. Este actuar, tiene sus límites en los principios constitucionales, dado que en el ejercicio de su capacidad normativa, las Comunidades Autónomas están sujetas al texto constitucional y a las leyes reguladoras de la financiación de las mismas, de forma que los tributos que les han sido cedidos por el Estado, en su aplicación, no deben suponer diferenciación de trato jurídico fiscal para los contribuyentes por la desigual ubicación geográfica de los mismos ${ }^{18}$.

Esta actuación de trato dispar está generando discrepancias entre la actividad de autonomía de las Comunidades Autónomas ${ }^{19}$ y el principio de igualdad, dado que la existencia de una diferenciación de trato entre grupos de personas produce discriminaciones significativas y por tanto, vulneración del principio de igualdad que debe presidir el sistema tributario español por exigencia constitucional.

En efecto, el principio de igualdad tributaria junto al de justicia tributaria presiden el sistema tributario y simbolizan la formación de los principios de capacidad económica y generalidad como garantía para que los contribuyentes reciban igual tratamiento impositivo en el acto del establecimiento y aplicación de los tributos. Estas desigualdades entre sujetos pasivos que ostentan el mismo indicador de riqueza y con idéntica base imponible, van a terminar siendo gravados de distinta forma, en función de la residencia habitual del causante y no por la capacidad que ostente el adquirente, por ser diferente el gravamen del tributo en una Comunidad Autónoma u otra, condicionando así, la deuda tributaria de la herencia. Por tanto, lo que impone el principio de igualdad para todos los españoles, es impedir en la configuración del impuesto la existencia de ciudadanos privilegiados en el territorio nacional ${ }^{20}$.

\footnotetext{
${ }^{17}$ Atendiendo a lo recogido por los artículos 139.2 y 157.2 de la Constitución española de 1978, para la imparcialidad y unidad del mercado, reclaman que, las Comunidades Autónomas no deben tomar medidas tributarias que impidan la libre circulación de bienes, mercancías, servicios, capitales y establecimiento de personas que perturben el mercado único del Estado.

${ }^{18}$ GARCÍA NOVOA, C., "La financiación de las Comunidades Autónomas a través de la Jurisprudencia del Tribunal Constitucional”, en VV.AA., Veinticinco años de financiación autonómica, Universidad de Cantabria, Parlamento de Cantabria, Santander, 2005, p. 162.

${ }^{19}$ Sirva como ejemplo la Comunidad de Madrid que fue la primera en llevar a cabo las reducciones en el Impuesto sobre Sucesiones y Donaciones, con la aprobación de la Ley 7/2005, de 23 de diciembre, de Medidas Fiscales y Administrativas, estableció para los residentes en territorio español, una reducción del 99\% sobre la base imponible, reservando el 1\% a simples efectos de control tributario. Este ejemplo, ha sido continuado en otras provincias, como Navarra, Cantabria y las Diputaciones forales de Vizcaya, Guipúzcoa y Álava, donde recibir la herencia no conlleva ningún gravamen. En el plano europeo, Italia ha suprimido el impuesto en transmisiones de padres a hijos, en Estados Unidos se ha elevado el mínimo exento hasta 3.5 millones de dólares. En este sentido, véase HERMOSÍN ÁLVAREZ, M., "La situación del Impuesto sobre Sucesiones y Donaciones como tributo cedido a las Comunidades Autónomas, Ejercicio 2010”, Revista de estudios regionales, n. 88/2010, p. 80. Completa que actualmente quedan algunas Comunidades que no han suprimido el impuesto a pesar de sus facultades, como Andalucía, Cataluña o Extremadura que aún estableciendo cambios, han sido poco populares.

${ }^{20}$ ALONSO GONZÁLEZ, L.M., La inconstitucionalidad del Impuesto sobre Sucesiones y Donaciones, Instituto de Estudios Económicos, Madrid, 2001, p. 10.
} 
En definitiva, las medidas aprobadas por las Comunidades Autónomas no deben acordar disposiciones que discriminen por motivo del término donde se encuentren ubicados los bienes recibidos gratuitamente. Estas técnicas, amenazan la estabilidad de dicha figura impositiva y devienen en diferentes posiciones doctrinales en favor o no, del mantenimiento del Impuesto sobre Sucesiones y Donaciones. Se considera pues que es un instituto cuestionado, de dudosa subsistencia ${ }^{21}$. Las voces que defienden su supresión, lo hacen por considerar que se trata de un impuesto obsoleto ${ }^{22}$, e injusto que afecta exclusivamente a los sujetos que no han planificado previamente la transmisión de la herencia. Mientras, las que apuestan por el mantenimiento del Impuesto defienden que el impuesto es útil para su fiscalidad y por tanto debe ser establecido con una tributación común de mínimos que respete la igualdad de todos los contribuyentes nacionales obedeciendo el mandato del principio de igualdad tributaria ${ }^{23}$.

Desde su pensamiento, decía Aristóteles que en el punto medio está la virtud, si se toma nota de ello, la ordenación del impuesto sobre Sucesiones y Donaciones vendría dada por mantenerlo, pues aun habiendo muchos argumentos para retirarlo (Discriminación, desigualdad, penalización del ahorro, insolidario e injusto, etc.) sería más oportuno reducirlo a unos mínimos nobles con un tipo único progresivo ${ }^{24}$, que implicara un gravamen equitativo y razonable influido por el principio de igualdad tributaria, en las mismas circunstancias para todos los contribuyentes del territorio nacional. En base a ello, debería ajustarse en unos cánones justicieros la capacidad normativa de las Comunidades Autónomas que lo han realizado según su conveniencia, con el resultado de un gravamen diferente en cada una de ellas ${ }^{25}$. De esta forma, serviría

21 Véase MERINO JARA, I., Impuesto sobre Sucesiones y Donaciones, Problemas actuales, Aranzadi, Navarra, 2001, p. 18.

${ }^{22}$ PEÑA ALONSO, J.L., "El ejercicio competencial de las Comunidades Autónomas en el Impuesto sobre Sucesiones y Donaciones, Un debate abierto”, en VV.AA., La reforma de los Estatutos de Autonomía, Revista jurídica de Castilla y León, Junta de Castilla y León, Valladolid, 2003, p. 513.

${ }^{23}$ CAZORLA PRIETO, L.M., "La agonía del Impuesto de Sucesiones”, Escritura Pública, n. 20/2003, p. 33. Advierte que las Comunidades Autónomas como el País Vasco y Navarra suprimieron la carga fiscal del Impuesto sobre Sucesiones al amparo de sus regímenes especiales, mientras que las Comunidades limítrofes Cantabria y La Rioja tuvieron que acudir a la jurisprudencia para buscar tal beneficio al amparo de la Ley 21/2001, de 27 de diciembre, de financiación de las Comunidades Autónomas, para regular la desigualdad de trato fiscal entre sujetos españoles.

${ }^{24}$ No hay duda que a través del principio de progresividad tributario se hace efectiva la distribución de la carga tributaria según la capacidad económica del contribuyente, y así se observa también en la aplicación progresiva del tipo único, si tomamos por ejemplo un tipo único del 5\% para todos los beneficiaros, estaríamos en que este porcentaje para 1.000 euros representaría $50 €$ y para $10.000 €$ sería $500 €$, con lo cual, el último estaría pagando 10 veces más gravamen que el anterior, que sería la proporción justa a su capacidad económica. RODRÍGUEZ BEREIJO, expresa al respecto, que "la progresividad tributaria constituye también una «medida de igualdad»" ("Los principios de la imposición en la jurisprudencia constitucional española”, Revista española de Derecho Financiero, Civitas, n. 100/1998, p. 621).

${ }^{25}$ Se puede decir, que la lucha para terminar con la discriminación en España a residentes en función de la Comunidad Autónoma en cuanto a la residencia del causante, no terminará hasta que sea llevada ante los Tribunales españoles. De momento, el heredero no tendrá la misma ventaja fiscal por motivos del lugar de residencia, si lo hace en Madrid o Andalucía. 
también como medio de control de la Hacienda Pública ${ }^{26}$, equilibrado para las clases más bajas, proporcionado, redistribuiría la riqueza y serviría como reclamo para invertir en España ${ }^{27}$. En la misma sintonía, es ineludible una regulación más precisa que establezca la relación fiscal hacia el ciudadano no residente, con las posibles reformas para su sostenimiento, en conexión con la CE y el régimen comunitario.

De no ser así, tales normas se moverían en continua oposición con la libertad de establecimiento que consagra el artículo 49 del Tratado de Funcionamiento de la Unión Europea, que según la jurisprudencia del TJCE no se puede condicionar el empleo de un beneficio fiscal sobre la adquisición, a que el domicilio del donatario se encuentre en una determinada Comunidad Autónoma. Ciertamente, este prototipo de ordenaciones reduce la consagración de significativos beneficios fiscales que obstaculizan la libertad de establecimiento.

\section{Vulneración de las libertades fundamentales en el Derecho Comunitario}

La posición del Impuesto para Sucesiones y Donaciones español en virtud del ejercicio competencial de las Comunidades Autónomas para residentes, tiene como resultado el establecimiento de una fiscalidad que no ha resultado homogénea en todo el término español, variando en aplicación del lugar en el que se produzca el hecho imponible, de tal modo, que lo recaudado por este impuesto se ha visto reducido al mínimo. Además, como el Estado se reserva la recaudación y gestión que por este impuesto corresponde a sujetos no residentes dentro del territorio nacional, que contribuyan por obligación real ${ }^{28}$, pertenece también al Estado su régimen jurídico. Esta

\footnotetext{
${ }^{26}$ En este sentido, señala FUENTES QUINTANA, que el Impuesto sobre Sucesiones y Donaciones sirve para "limitar el derecho de una persona a adquirir riqueza por medio de legados sin su propio esfuerzo" (Hacienda Pública, Principios y estructura de la imposición, Universidad Complutense, Vol. II, Madrid, 1987, pp. 310 y 312).

${ }^{27}$ La Teoría de la ilusión financiera que defendía PUVIANI, bien podía ser aplicada a la actual lucha que se viene produciendo contra el Impuesto sobre Sucesiones y Donaciones en nuestro país, donde se pone de manifiesto que la carga tributaria es perjudicial para los más débiles económicamente, cuando es indudable que la eliminación efectiva del impuesto, será en todo caso, más beneficiosa para las esferas que más potestad tienen a la hora de recibir herencias (Teoría de la ilusión financiera, Instituto de Estudios Fiscales, Ministerio de Economía y Hacienda, Madrid, 1972, p. 27).

${ }^{28}$ Para MARTÍN ROMÁN Y DEL BLANCO GARCÍA, la mención del valor real puede suponer una inseguridad jurídica, dado que la Ley 29/1987, de 18 diciembre del Impuesto sobre Sucesiones y Donaciones no lo desarrolla, dejando un amplio margen a la Administración para definirlo según sus prioridades. Por su parte "el Tribunal Constitucional en su Sentencia 194/2000, de 19 julio (FJ 7), ha señalado que declarar un valor real es una magnitud indeterminada en tanto no se determine qué debe entenderse por valor real, ni se especifiquen los parámetros que deban emplear los sujetos pasivos del impuesto para determinarlo, razón por la cual las discrepancias en relación con los bienes y derechos no sólo son lógicas y razonables, sino incluso frecuentes" ("La problemática de las sucesiones transfronterizas en Europa”, Crónica tributaria, n. 151/2014, pp. 140).
} 
situación ha dado lugar a una discriminación entre residentes y no residentes, con la repercusión de una mayor tributación para los no residentes por la aplicación de la normativa estatal que es más onerosa.

La incorporación al Tratado de Funcionamiento de la Unión Europea nos ha pasado a ser parte del actual acervo comunitario, con el resultado de que puede ser ciudadano de la Unión todo sujeto que posea la nacionalidad de un Estado miembro, así la ciudadanía europea se une a la nacional pero sin reemplazarla ${ }^{29}$. Esta determinación intensifica la prohibición de discriminación a cualquier ciudadano y da derecho a que se adquiera idéntico trato legal cuando se halle en igual situación, resultando indiferente la nacionalidad a que se pertenezca.

Actualmente, la ciudadanía de la Unión Europea impone a los Estados miembros, en relación con sus mismos ciudadanos como de otros Estados miembros, las mismas limitaciones que resultan del ejercicio de las libertades fundamentales contenidas en el Tratado. Teniendo en cuenta, que estos derechos sobre la libre circulación y residencia sólo serán atribuidos a los individuos nacionales de un Estado miembro de la Unión Europea, quedará desamparado cualquier desplazamiento que se realice fuera de la ella.

Con todo, cabe precisar, que la ciudadanía de la Unión Europea no entra a juzgar el poder de los Estados miembros para fijar los criterios de aplicación en su legislación tributaria interna por el Impuesto sobre Sucesiones y Donaciones, siempre que la utilización de sus normas vayan dirigidas a sus propios nacionales y no a los de otros Estados miembros, hecho que no resulta contrario al principio de no discriminación por atribución de nacionalidad. De igual manera, la ciudadanía de la Unión y su derecho a desplazarse y a fijar residencia no puede encontrar imparcialidad tributaria para sus contribuyentes, por la disparidad que existe entre los distintos sistemas tributarios de los Estados. Es decir, los Estados tienen el poder de realizar y fijar sus tributos dentro de su territorio, pero lo que no pueden hacer es tener un baremo de gravamen muy distinto para los ciudadanos residentes y otro más gravoso para los ciudadanos no residentes.

En este contexto, donde la normativa interna de los Estados sigue siendo incompatible entre ambos sujetos pasivos, residentes y no residentes, ha propiciado que desde la Comisión Europea se hayan solicitado nuevos cambios en la legislación española, en relación con la tributación del Impuesto sobre Sucesiones y Donaciones aplicado a los no residentes por las fortunas emplazadas en el extranjero, fundamentando que las leyes actuales siguen siendo contradictorias con la libre circulación de capitales.

En la actualidad, la legislación de España (aunque con algunas modificaciones)

\footnotetext{
${ }^{29}$ Véase en materia de nacionalidad a efectos tributarios a LÓPEZ ESPADAFOR, C.M., "Los preceptos de naturaleza tributaria en la legislación sobre extranjería tras su reforma”, en la Revista española de Derecho Financiero, Civitas, n. 154/2012, p. 89.
} 
continúa siendo incompatible con el Derecho de la Unión Europea por cuanto se ha puesto de relieve que la regulación del Impuesto sobre Sucesiones y Donaciones parece no haber modificado sustancialmente su forma discriminatoria. Lo que demanda la jurisprudencia comunitaria es que se emprendan cambios legislativos por parte de la normativa estatal para regular de modo diferente el ejercicio de las competencias normativas de las Comunidades Autónomas, que permitan aproximar el gravamen fiscal del ISD para residentes y no residentes y se adecue a lo señalado en los artículos 45 y 63 del Tratado de Funcionamiento de la Unión Europea (TFUE) ${ }^{30}$.

Como era de esperar, la jurisprudencia del Tribunal de Justicia de La Unión Europea no podía admitir la existencia de discriminaciones por argumentos dominantes de carácter general, y así, se ha pronunciado a favor de lo suplicado por la Comisión Europea de someter este asunto a su criterio, demandando por ello al Estado español ${ }^{31}$.

En efecto, el Tribunal de Justicia de las Comunidades Europeas en su Sentencia de 3 de septiembre de 2014, Comisión Europea contra Reino de España, asunto C-127/12, ha expuesto una posición discriminatoria contraria a la libre circulación de capitales. Aclarando una de las irregularidades de la actual normativa del Impuesto sobre Sucesiones y Donaciones en España, cual es, la discriminación en torno a los no residentes en España ${ }^{32}$.

Tomando como base, que si el causante o donatario son residentes en España, se les asigna la legislación territorial, donde los contribuyentes se favorecen de los privilegios fiscales autonómicos. Mientras que, cuando el causante o donatario son residentes en el extranjero se les asigna la normativa estatal, sin que los contribuyentes tengan opción a los beneficios fiscales autonómicos, instituyendo así, un escenario discriminatorio contradictorio con la libre circulación de capitales, que está legitimada por el artículo 63 del Tratado de Funcionamiento de la Unión Europea ${ }^{33}$.

\section{LAS FUNCIONES DE LA RESIDENCIA FISCAL EN EL DERECHO DE LA UNIÓN EUROPEA}

\footnotetext{
${ }^{30}$ MARTÍN ROMÁN, J. y DEL BLANCO GARCÍA, A.J., op. cit., p. 137.

${ }^{31}$ Se da la paradoja, que este proceder de las Comunidades Autónomas de tener distintas normativas en el régimen interno, creando una exagerada desigualdad tributaria entre los mismos ciudadanos españoles, no es sostenible y será el principio de igualdad quien reclamará el mismo proceder en todas las Comunidades Autónomas para acabar con este problema, que si no se resuelve por vía legislativa, tendrá que hacerse jurisdiccionalmente en forma de cuestión de inconstitucionalidad ante el Tribunal Constitucional (CAZORLA PRIETO, L.M., op. cit., p. 33).

${ }^{32}$ GARCÍA DE PABLOS, J.F., "La urgente reforma del Impuesto sobre Sucesiones y Donaciones en España a la luz del derecho comunitario”, Quincena fiscal, n. 18/2014, pp. 134 y 135.

${ }^{33}$ El Tratado de Funcionamiento de la Unión Europea consagra en su artículo 63.1 que "en el marco de las disposiciones del presente capítulo, quedan prohibidas todas las restricciones a los movimientos de capitales entre Estados miembros y entre Estados miembros y terceros países”.
} 
El Tribunal de Justicia de la Unión Europea ha considerado que las transmisiones lucrativas crean desplazamientos de capital, y que, las reducciones de capitales constituyen normas tributarias que causan disminución del valor de la herencia o donación por la mayor tributación recibida, en función de la residencia del causante o del heredero o de la situación del bien gravado. Interpreta por ello, que en el actual sistema español, donde el reparto de competencias entre el Estado y las Comunidades Autónomas establece una discriminación no justificada, en atención a la residencia, que deriva en la adjudicación de privilegios fiscales autonómicos cuando el fallecido o beneficiario residan en España, con resultado discriminatorio para los habitantes no residentes que a la hora de pagar el impuesto se les aplicará las normas estatales, no pudiendo ser beneficiarios de la legislación autonómica.

En materia tributaria, la idea de justicia e igualdad ha venido dada por la propia evolución social de nuestra sociedad actual, que ha devenido en la plasmación de normas y la concreción de los principios materiales tributarios que constitucionalmente los mantienen jurídicamente. Este modelo, debería obligar a actuar de acuerdo con los mismos planteamientos a los distintos sistemas jurídicos dentro del territorio español en el Impuesto sobre Sucesiones y Donaciones. El sometimiento de tributación de este impuesto a la descentralización territorial, le ha llevado a tener veinte formas distintas de gravamen, con quince Comunidades Autónomas de régimen común, más Navarra y las tres provincias vascas, y además el régimen jurídico aplicado por el Estado a los no residentes, para el que no existen beneficios ${ }^{34}$.

Ante estas continuas e incesantes diferencias de trato fiscal, conviene recordar, que la Comisión Europea solicitó a las autoridades españolas en varias ocasiones que se cambiara la normativa interna realizada por la Ley 29/1987, de 18 de diciembre, del Impuesto sobre Sucesiones y Donaciones y ratificada posteriormente por los artículos 32 y 48 de la Ley 22/2009, de 18 de diciembre, que regulaba el Sistema de Financiación de las Comunidades Autónomas de Régimen Común, dado que quebrantaba la legislación europea que protege la libre circulación de capitales, y ante su impasibilidad formalizó recurso en marzo de 2012 contra el Estado español. Súplica, que no llegó a ser atendida por el Gobierno español que tuvo la oportunidad de adecuar nuestro derecho al de la Unión Europea y haber aclarado las dudas que sobre la variación del impuesto nos exigía Bruselas.

Tomando en consideración la jurisprudencia sentada por el Tribunal de Justicia de la Unión Europea ${ }^{35}$, llevará a modificar la normativa española contenida en la Ley

\footnotetext{
34 CALVO ORTEGA, R., “Financiación de las Comunidades Autónomas y constitución”, Nueva Fiscalidad, n. 1/2008, p. 16.

35 El Tribunal de Justicia de la Unión Europea ha analizado la compatibilidad de determinadas medidas aprobadas por los Estados miembros en relación con la libertad de establecimiento en su jurisprudencia. Podemos destacar su Sentencia de 25 de octubre de 2007, Maria Geurts y DennisVogten contra Administratie van de BTW, registratie en domeinen (Administración del IVA, de Registros y del Patrimonio del Estado), Belgische Staat (concretando “autoridades tributarias belgas”), asunto C-464/05,
} 
22/2009, de 18 de diciembre, de transferencia del Impuesto sobre Sucesiones y Donaciones a las Comunidades Autónomas, de forma que los ciudadanos no residentes en España puedan favorecerse de los beneficios fiscales autonómicos en igualdad de condiciones $^{36}$. Transformación que cabría extraerle provecho para realizar la modernización en la imposición de las transmisiones lucrativas en el Estado español, en armonía con el novedoso informe Lagares $^{37}$ sobre la mejora del sistema tributario español. Esta consideración iba a ser premonitoria de lo que después ha acontecido, porque definitivamente el Tribunal de Justicia de la Unión Europea ha dictado sentencia el 3 de septiembre de 2014 por la que ha declarado el incumplimiento por parte del Estado español del artículo 63 del TFUE, así, como el artículo 40 del Acuerdo sobre el Espacio Económico Europeo, rubricado en Oporto el 2 de mayo de 1992, al consentir diferencias en el trato fiscal sobre las sucesiones y donaciones a los no residentes.

\section{El problema comunitario del Impuesto sobre Sucesiones y Donaciones para evitar dobles imposiciones}

Causan las sucesiones que operan por encima de las fronteras dificultades, que para encararlas en relación al procedimiento legal que se aplica para prevenir la doble imposición internacional ${ }^{38}$. Ha divulgado la Comisión Europea con fecha 15 de

que tiene como antecedentes jurisprudenciales la Sentencia de 11 de diciembre de 2003, Herederos de Sr. H. Barbier contra Inspecteur van de Belastingdienst Particulieren/Ondernemingen buitenland te Heerlen (inspector de la administración tributaria, unidad "personas físicas/empresas extranjeras”, de Heerlen), asunto C-364/01 y la Sentencia de 23 de febrero de 2006, Herederos de M.E.A. Van Hilten-van der Heijden contra Inspecteur van de Belastingdienst/Particulieren/Ondernemingen buitenland te Heerlen (inspector de la administración tributaria, unidad “personas físicas/empresas extranjeras”, de Heerlen), asunto C-513/03.

${ }^{36}$ Para muchos autores, la solución en cuanto a los no residentes a fin de equipararlos cuantitativamente, con los contribuyentes residentes, pasaría por situarlos en un plano de igualdad. RIBES RIBES, A., "La tributación sucesoria de los no residentes en España a la luz de la doctrina del Tribunal de Justicia de las Comunidades Europeas”, Revista técnica tributaria, n. 88/2010, p. 113.

${ }^{37}$ El informe emitido por la Comisión de Expertos para la Reforma del Sistema Tributario, presidida por Manuel Lagares Calvo, dictado el 14 de marzo de 2014, programa una modificación global del sistema fiscal español que contribuya a modernizar el sistema tributario, en aras de conseguir que los impuestos sirvan para ayudar al progreso y al crecimiento, en armonía con las indicaciones realizadas recientemente por los organismos Internaciones de la Unión Europea. En relación a nuestro sistema fiscal, destaca que la consolidación fiscal debe ser la prioridad en estos momentos y, una de sus consecuencias debe lograrse a través de aumentar la tributación de los inmuebles, pero reduciendo la de sus transmisiones. Para el logro de esta propuesta de reforma fiscal, debe estar regida por la justicia en la imposición, la igualdad tributaria como trato igual a los iguales y máxima coordinación en el Impuesto de Sucesiones. Una de las principales propuestas, que se observa, se basa en mantener un elevado grado de centralización en la gestión tributaria del Impuesto sobre Sucesiones y Donaciones pretendiendo con ello, que no existan desigualdades que perjudiquen a la libre circulación de capitales y dificulten las transacciones.

${ }^{38}$ El condicionamiento internacional de cualquier medida es cada vez más evidente, como se pone de manifiesto en LÓPEZ ESPADAFOR, C.M., "Premesse internazionali dell'evoluzione della sovranità tributaria”, en Rivista di diritto tributario internazionale, n. 3/2013, p. 7. 
diciembre de 2011, una Recomendación, donde se instituyen diferentes reglas a alcanzar para impedir el cúmulo impositivo por los Estados miembros y enmendar la situación, ante la inexistencia de recursos eficaces en este ámbito, que puedan atender el incremento de desplazamientos transfronterizos, adonde el principio de libertad de circulación de personas, capitales, mercancías y servicios, suponen los fundamentos del mercado único europeo, donde surgen los problemas derivados de la doble imposición ${ }^{39}$.

En este orden, la Unión Europea ha contemplado en numerosas Comunicaciones que los elementos existentes anunciados para evitar la doble imposición no son efectivos en lo concerniente a los impuestos sobre sucesiones, siendo necesario herramientas más específicas de fiscalidad. Para ello, la Comisión Europea ante el supuesto de que un mismo hecho tributario pueda ser susceptible de gravamen en varios Estados, ha mostrado su inquietud sobre la discordancia que existe de fundamento para la tributación tanto en la Unión como en España, debido a que en la actualidad no imperan cánones de armonización en la regulación de los impuestos sobre sucesiones, porque son competencia de los Estados miembros, aunque siempre desde el respeto a las libertades fundamentales ofrecidas en la legislación comunitaria.

A estos fines, en los casos de una sucesión transnacional, puede ocurrir que haya más de un Estado miembro que tenga autoridad tributaria y aunque su normativa interna atempere la doble imposición, puede terminar creando impedimentos reales para los ciudadanos comunitarios en la actuación de su derecho a circular por los límites fronterizos de la Unión Europea, e incluso entorpecer el traspaso de empresas una vez fenecido su dueño.

Con la finalidad de subsanar la ineficacias y promover la facilidad de las prevenciones nacionales, se ha propuesto por parte de la Comisión un orden de primacía en las desgravaciones fiscales en los casos de colisiones entre dos o más Estados miembros a la hora de aplicar impuestos sobre sucesiones para el caso de una misma herencia. De ahí, que la Recomendación de la Comisión haya establecido unos objetivos que solucionen los asuntos de doble imposición para que la imposición tributaria general que soporte una sucesión no sea superior a la aplicada por un solo Estado miembro.

En base a ello, la Recomendación propone a los Estados miembros que permitan exenciones fiscales de los impuestos sobre sucesiones que ya hubieran sido aplicados por otro Estado miembro a bienes inmuebles en su territorio, permitiendo a su vez, que dichas desgravaciones permanezcan durante un periodo de tiempo razonable, así como el respeto para la realización de acuerdos que puedan resolver conflictos de doble imposición ${ }^{40}$. Si bien, la Comisión no ha propuesto ninguna disposición legal

\footnotetext{
${ }^{39}$ Sobre la situación actual del fenómeno de la doble imposición, vid. LÓPEZ ESPADAFOR, C.M., La doble imposición, Problemática actual, La Ley, Madrid, 2012.

${ }^{40}$ MARTÍN ROMÁN, J. y DEL BLANCO GARCÍA, A.J., op. cit., p. 117.
} 
en relación con la doble imposición, si tiene la oportunidad de realizarlo más tarde si lo creyese oportuno ${ }^{41}$.

Por otro lado, la Comisión seguirá realizando un exhaustivo seguimiento de las normativas y prácticas de los diferentes Estados miembros en relación con la tributación de las herencias, para valorar las modificaciones que se produzcan en atención a las propuestas de la Recomendación, así, como la magnitud y eficacia de las mismas para evitar la doble imposición en el impuesto de Sucesiones.

Dentro del marco legislativo de utilidad en España en conexión a la materia tributaria de sucesiones, se estipulan medidas unilaterales intrínsecas y convenios bilaterales suscritos con otros países de la Unión Europea. La principal normativa es la Ley que regula el impuesto sobre Sucesiones y Donaciones, en la que se define la forma de tributar por obligación personal para los residentes y por obligación real para los no residentes. En su artículo 23 se dispone el dispositivo para evitar la doble imposición a través de una atribución reducida. Según dicta el referido precepto, los residentes españoles que estén sometidos a tributar en el extranjero tendrán derecho a deducir la menor de las cuotas que conciernen al incremento patrimonial subordinado a gravamen de un impuesto similar. De igual forma se empleará la deducción por doble imposición comunitaria regulada en el artículo 46 del Reglamento del Impuesto sobre Sucesiones y Donaciones.

Consecuentemente, para la aplicación de la ley tributaria española en las sucesiones con elemento internacional, deberá tenerse en cuenta la residencia fiscal del difunto, la del heredero y donde están localizados los activos del patrimonio a gravar, por ser el único factor internacional el lugar de establecimiento de los bienes o derechos de la herencia. En caso de residir los últimos cinco años antes de su fallecimiento en una Comunidad Autónoma se aplicará la legislación de esta.

No obstante, entendemos que para dar cumplimiento al propósito de la Recomendación para que la carga global de una sucesión no supere la que sería de aplicación si solamente gozase de competencia fiscal un Estado, en este caso, España sobre toda ella. En este sentido, el artículo 23 de la Ley sobre el Impuesto de Sucesiones y Donaciones no asegura que la carga tributaria final no prevalezca a la que pueda derivarse por dos Estados miembros.

\footnotetext{
${ }^{41}$ LÓPEZ ESPADAFOR, C.M., "La exención en el Impuesto sobre la Renta de las Personas Físicas de rendimientos de trabajo obtenidos en el extranjero”, Crónica tributaria, n. 96/2000, pp. 83 y 84. Concreta el autor que a veces y en determinados casos, en vez de realizar una deducción frente a la doble imposición comunitaria, se procede permitiendo que las rentas conseguidas que ya hayan tributado en otro Estado miembro queden exentas, en este caso, cambia la situación y habrá que sugerir si se estaría hablando entonces, de doble imposición. En teoría, prosigue, pueden defenderse varios métodos de actuación sobre la doble imposición internacional, por un lado, la normativa de origen interno de cada Estado, y por otro, los convenios internacionales para delimitar la forma más adecuada en cada caso e impuesto.
} 
Finalizado el análisis del interior de la Recomendación de la Comisión que apunta cuantiosas disposiciones dirigidas a impedir la doble imposición en tema de sucesiones, en analogía a esta temática, realiza el análisis de qué legislación es de empleo en España. A pesar de que la vasta normativa se haya instituido por instrumentos unilaterales autorizadas por nuestro país, es verdad que además se han firmado convenios bilaterales con ciertos países de la Unión Europea, a pesar de que la amplitud de éstos esté muy delimitada.

Asimismo, el cómputo de convenios establecidos en la Unión Europea para combatir la doble imposición en el ámbito de sucesiones, es hasta cierto punto insignificante, dado que en muchos países no recaudan por este impuesto, no obstante, es necesario la aplicación de convenios para evitar la doble imposición.

\section{Dictamen de la Sentencia del Tribunal de Justicia de la Unión Europea DE 3 DE SEPTIEMBRE DE 2014 (ASUNTO C-127/12), COMISIÓN EUROPEA CONTRA REINO DE ESPAÑA}

Dentro de los procesos de control abstracto de la ley por parte del Tribunal de la Unión Europea, se defiende que la normativa de un Estado miembro que hace depender la aplicación de una reducción de la base imponible de la sucesión o donación del lugar de residencia del causante, dando lugar a que soporten una mayor carga fiscal los no residentes que los residentes, constituye una restricción de la libre circulación de capitales $^{42}$.

En efecto, hemos asistido hace pocos meses, a instancia del recurso por incumplimiento interpuesto por la Comisión Europea, la presunta vulneración por parte del Reino de España de las obligaciones referentes al derecho de libre circulación de capitales como consecuencia de las diferencias instituidas en el trato fiscal diferenciando entre residentes y no residentes en la legislación reguladora del Impuesto sobre Sucesiones y Donaciones en España. Si lo reclamado hubiera sido por una cuestión prejudicial solicitada por un tribunal español, sus efectos se limitarían a la cuestión que motivó la consulta. Al ser por un recurso de la Comisión Europea sus efectos son muchos más amplios.

\footnotetext{
${ }^{42}$ Véanse, en este sentido, en materia de donación, la Sentencia de 22 de abril de 2010, Vera Mattner contra Finanzamt Velbert, asunto C- 510/2008, apartado 28 y, en materia de sucesión, la Sentencia de 17 de octubre de 2013, Yvon Welte contra Finanzamt Velbert, asunto C- 181/2012, apartado 25. Lo más destacado de ellas, es precisar que los sujetos pasivos residentes o no residentes del Impuesto sobre Sucesiones se encuentran en el mismo plano comparable, al igual que precisa, que se protege la libre circulación de capitales de los residentes en otro país tercero a efectos fiscales (HERRERA MOLINA, P.M., "STJUE Welte: ¿el fin de las reducciones y beneficios fiscales autonómicos en el impuesto sobre sucesiones?”, ECJ Leading Cases, 2013, consultado el 13 de junio de 2015, en https://ecjleadingcases.wordpress.com/2013/10/22/stjue-welte-el-impuesto-sobre-sucesiones-no-puedediscriminar-a-los-no-residentes/
} 
El fundamento de esta decisión de la Justicia Europea es la limitación de la legislación estatal a la hora de aplicar la normativa de las diferentes Comunidades Autónomas a los residentes en territorio español, lo que permite un trato diferente a los sujetos pasivos de otros Estados miembros en ejercicio de su residencia, aún cuando se encuentren en unas condiciones confrontables, lo que constituye una restricción de la libre circulación de capitales y, consecuentemente, una vulneración de la normativa comunitaria.

En efecto, en esta sentencia, la decisión adoptada por el Tribunal de Justicia de la Unión Europea ha sido que la legislación estatal española permite un trato distinto a los sujetos pasivos por razón de su residencia ${ }^{43}$, aun cuando se encuentren en una misma situación, al limitar la aplicación de la normativa de las Comunidades Autónomas a los residentes en España, así como a los inmuebles afincados en territorio español, lo que configura una restricción de la libre circulación de capitales y, por ende, una vulneración de la normativa comunitaria bien inmueble.

Por tanto, lo que critica la justicia europea es que los no residentes no puedan favorecerse de los beneficios y deducciones autonómicas en el Estado español, obligando con ello, a pagar más tributo a los que residen dentro de otro Estado miembro, razonando que el Impuesto sobre Sucesiones y Donaciones vulnera, la legislación comunitaria.

En consecuencia, ante este nuevo toque de atención por la jurisprudencia europea al Estado español, pasamos a desgranar el dictamen de esta resolución, por incumplimiento de Estado; libre circulación de capitales; artículos 21 y 63 Tratado de Funcionamiento de la Unión Europea; Acuerdo EEE, artículos 28 y 40; Impuesto Sobre Sucesiones y Donaciones; reparto de las competencias fiscales; discriminación entre residentes y no residentes; discriminación en función del lugar donde está situado el bien inmueble.

La Sentencia del Tribunal de Justicia de la Unión Europea de 3 de septiembre de 2014, asunto C-127/12, Comisión europea contra Reino de España, ha juzgado el incumplimiento de un Estado miembro, en el ejercicio de aplicación de la legislación estatal y, declara que de acuerdo con los artículos 63 Tratado de Funcionamiento de la Unión Europea y 40 del Acuerdo sobre el Espacio Económico Europeo, de 2 de mayo de 1992, condena al Estado español por la aplicabilidad de la normativa de la Ley del Impuesto sobre Sucesiones y Donaciones, en contra de la prohibición comunitaria de restringir la libre circulación de capitales en la Unión Europea, permitiendo el establecimiento de diferencias en el trato fiscal de las donaciones y sucesiones, ya que discrimina principalmente a los no residentes frente a los residentes en territorio español y en las disposiciones análogas de bienes inmuebles que radican en España y fuera de

\footnotetext{
${ }^{43}$ Se ha reconocido que la residencia fiscal se ha consolidado como el criterio principal, por ser el que mejor sintetiza la distribución individual de las cargas tributarias por un impuesto (GARCÍA PRATS, F.A., "La residencia fiscal y el Derecho Comunitario”, Crónica tributaria, n. 146/2013, p. 155).
} 
ésta.

Importa reseñar, por ser ilustrativo, que constituyen restricciones de los movimientos de capitales las medidas nacionales que causan una disminución del valor heredado o de la donación de un residente perteneciente a un Estado distinto del territorio donde se graven o se hallen los bienes afectados. Señala el Tribunal en la sentencia que cualquier diferencia de trato presupone una discriminación.

El debate se centra en el tratamiento que reciben las herencias y donaciones a la hora de tributar, teniendo en cuenta si es residente o no para nuestra legislación interna, dado que se puede observar, que en los artículos 32 y 48 de la Ley 22/2009, de 18 de diciembre, se regula tácitamente que las Comunidades Autónomas pueden disponer bonificaciones fiscales aplicables sólo a quien tenga punto de conexión con las mismas. De ello se deduce claramente, que quienes no sean residentes en territorio español, no lograrán favorecerse de las mimas, por aplicación del gravamen estatal, lo que repercutirá en una reducción de la herencia. Si el impuesto es un tributo estatal, por ende, le corresponde al Estado estructurar su carácter, con el objetivo de que su desarrollo sea homogéneo y garantice la coherencia de todo el sistema tributario ${ }^{44}$.

Entiende el Tribunal que en nuestro reglamento interno del Impuesto sobre Sucesiones y Donaciones, se considera a todos los contribuyentes herederos 0 donatarios, sean residentes o no, como sujetos pasivos que deben sufragar el impuesto, entonces, cabe preguntarse, que diferencia objetiva existe que pueda atribuirse 0 sustentar la diferencia de trato, sin que exista discriminación.

Aclara el Tribunal de Justicia de la Unión Europea, que de modo alguno, se intenta poner en discusión la competencia que le ha sido atribuida a cada Comunidad Autónoma, en cuanto a la fiscalidad del Impuesto sobre Sucesiones y Donaciones, exclusivamente se pone en cuestión el tema del criterio de conexión introducido por la legislación española, que permite sólo a las herencias y donaciones deducciones cuando los sujetos pasivos son residentes en su territorio.

Avanza también la jurisprudencia, que las medidas prohibidas en el artículo 63.1 del Tratado de Funcionamiento de la Unión Europea, por analogía, encierran también especialmente, todas aquellas que puedan a través de la restricción de los movimientos de capitales, disuadir a los no residentes de efectuar adquisiciones en cualquier Estado miembro. No obstante, para que la distinción entre residentes o no que distingue la normativa nacional española, logre considerarse compatible con el artículo 65.3 del Tratado de Funcionamiento de la Unión Europea en cuanto a esta restricción, será necesario que la diferencia de trato no sea objetivamente equiparable o esté justificada por razones de interés general. Asimismo, la vulneración del artículo 40 del Acuerdo sobre el Espacio Económico Europeo, tiene su fundamento en el artículo 63 del Tratado

\footnotetext{
${ }^{44}$ STC 181/1988, de 13 de octubre (FJ 5).
} 
de Funcionamiento de la Unión Europea dado que las disposiciones de ambos poseen igual importancia jurídica y disposiciones idénticas.

La jurisprudencia europea ha dado la razón al ejecutivo comunitario que llevó el caso a los tribunales en 2012, castigando a España a reformar la Ley del Impuesto sobre Sucesiones y Donaciones. Las consecuencias de la misma, es que todos los beneficiarios de una idéntica herencia o donación, tributarán con los mismos beneficios, terminando así con las discriminaciones de trato.

Pero su planteamiento, lleva consigo significativos y complejos cambios, al tratarse de una resolución que no admite recurso y, por ello, es de obligado cumplimiento para el Estado español, pues es sabido, que el Impuesto sobre Sucesiones y Donaciones se aplica en todo el territorio nacional, con las únicas excepciones de las provincias Vascas y de Navarra.

Las consecuencias más inmediatas y los efectos más convenientes que tiene la correcta aplicación del fallo, deberán ser la devolución de los pagos indebidos a raíz de la solicitud de los contribuyentes comunitarios no residentes en España que se han visto perjudicados por la aplicación del Impuesto sobre Sucesiones y Donaciones, con un plazo que se adecua al nacimiento de la norma. Seguida de una reforma de adaptación de nuestra normativa a la establecida por la Unión Europea para evitar dicha discriminación. Sin olvidar, que el Estado tendrá que soportar la responsabilidad patrimonial ante el derecho de los afectados de la Comunidad Europea.

Es evidente, que esta sentencia sugiere una reflexión crítica sobre las diferencias de trato fiscal ente residentes y no residentes en el territorio español, permitiendo que a partir de ella, si queremos recurrir, la actuación de los jueces y tribunales españoles deberá basarse en interpretar y aplicar la normativa actual conforme a la misma y a la jurisprudencia comunitaria, en aras de erradicar las discriminaciones existentes anteriormente.

Hacienda en un alarde de comprensión, se comprometió a realizar la devolución de los pagos indebidos por el Impuesto sobre Sucesiones y Donaciones, pero la realidad es que aún no ha abordado varios de los aspectos recomendados por el Informe de la Comisión de Expertos designada por el Gobierno para afrontar una Reforma del Sistema Tributario Español, que sería de especial utilidad como es la modificación y armonización del Impuesto.

Sin embargo, en virtud de esta Sentencia del Tribunal de Justicia de la Unión Europea, manifestándose sobre la ejecución de lo demandado por la Comisión Europea sobre la reforma del Impuesto sobre Sucesiones y Donaciones, y corregir al legislador estatal para indicarle el correcto acatamiento del Derecho comunitario, por el incumplimiento de las obligaciones que incumben con arreglo a 63 Tratado de Funcionamiento de la Unión Europea y 28 y 40 del Acuerdo sobre el Espacio Económico Europeo, debería haber sido prioritaria para el Gobierno español, adecuándose a los términos requeridos por la Comisión Europea, pero éste ha 
manifestado en el mes de agosto pasado, que la citada reforma junto a otros tributos cedidos no se llevaría a cabo hasta 2016, conjuntamente con un nuevo modelo para la financiación autonómica, pero parece más posible, que habrá que esperar nuevos aires para llevarla a su fin.

Por último, es preciso recordar, que la consecuencia final y más relevante que se deriva de esta importante sentencia es que, España ha incumplido la normativa comunitaria y por ello, deberá modificar la legislación interna reguladora del Impuesto sobre Sucesiones y Donaciones a la mayor brevedad posible, con el fin de excluir las desigualdades marcadas por el Tribunal de Justicia de la Unión Europea, referentes a la vulneración de la libre circulación de capitales, en el trato dado a la tributación de herencias y donaciones que reciben los residentes respecto de los que no lo son. De esta actuación se deriva, que la Hacienda pública española tendrá que hacer frente al reembolso de lo pagado incorrectamente por los contribuyentes comunitarios que así lo soliciten, cualquiera que haya sido el momento del pago de su autoliquidación (se estima, que deberá devolver unos doscientos millones de euros de los setecientos recaudados).

Además, dada la primacía del Derecho de la Unión Europea, su aplicabilidad es directa, y con efectos retroactivos desde la fecha en que se aprobó la Ley 29/1987, de 18 de diciembre, del Impuesto sobre Sucesiones y Donaciones, que ahora ha sido proclamada por el Tribunal de Justicia de la Unión Europea opuesta al Derecho Comunitario.

En esta misma línea, se ha manifestado el Tribunal Constitucional en su Sentencia 145/2012, de 2 de julio (FJ 6), al expresar, que el carácter ejecutivo de las Sentencias del Tribunal de Justicia de la Unión Europea dictadas en un procedimiento por incumplimiento, garantizan sus consecuencias inmediatas, y sus efectos ex tunc proyectan la eficacia de sus fallos al momento de entrada en vigor de la norma interna que ha sido estimada contraria al Derecho de la Unión Europea, y no a la fecha en que se dictan dichas Sentencias. Dejando sin efecto a la disposición desplazada aun cuando no haya sido destituida del ordenamiento interno. Al mismo tiempo dispone que su eficacia retroactiva vincula a los tribunales y Administraciones Públicas del Estado condenado.

VI. MODIFICACIÓN DE LA LEY 29/1987, DE 18 DE DICIEMBRE, DEL IMPUESTO SOBRE SUCESIONES Y DONACIONES, NUEVA REDACCIÓN A SU DISPOSICIÓN ADICIONAL SEGUNDA, DADA POR LA DISPOSICIÓN FINAL TERCERA DE LA LEY 24/2014, DE 27 DE NOVIEMBRE

El Gobierno de España consciente de la incompatibilidad que suponen algunos aspectos de la legislación estatal del Impuesto sobre Sucesiones y Donaciones, se ha puesto a trabajar, con el ánimo de eliminar los supuestos de discriminación definidos en la Sentencia del Tribunal de Justicia de la Unión Europea de 3 de septiembre de 2014, 
asunto C-127/12, Comisión europea contra Reino de España y evitar cualquier sanción por incumpliendo.

La Ley 29/1987, de 18 de diciembre, de Sucesiones y Donaciones ha introducido modificaciones, dando nueva transcripción a la disposición adicional segunda, con la idea de intentar equiparar el tratamiento fiscal entre los contribuyentes residentes y no residentes. La reforma tiene como finalidad eliminar los supuestos de discriminación y la igualdad del tratamiento en el impuesto para los contribuyentes no residentes que sean residentes en un Estado miembro de la Unión Europea o del Espacio Económico Europeo, distinto a España. Con estas medidas gozarán del derecho a la aplicación de la normativa correcta aprobada por la Comunidad Autónoma de que hubiera sido residente.

Con la redacción actual en la mano, seguirían existiendo dos categorías de no residentes en España, aquellos que no son residentes en España pero sí lo son en estados miembros de la Unión Europea o del Espacio Económico Europeo y por ello será de aplicación las reglas de la modificación, mientras que los no residentes en España pero que tampoco lo son en un Estado miembro, sino en un país tercero, les sería aplicable la normativa estatal, con lo cual, como ha dicho el Tribunal de Justicia de la Unión Europea, la libre circulación de capitales también es extensible a países terceros, por tanto, es de igual forma discriminatorio. Esta deficiente redacción podría deberse a la premura en la modificación del texto normativo a efectos de evitar posibles sanciones.

La nueva redacción de la Ley 29/1987, de 18 de diciembre, de Sucesiones y Donaciones, ha entrado en vigor el 1 de enero de 2015. Con estas nuevas propuestas, se ha intentado equiparar a los residentes en España con los no residentes que lo sean en un Estado miembro de la Unión Europea o del Espacio Económico Europeo, pero esta igualación lleva consigo cargar con las mismas desigualdades que sufren los residentes en España por aplicación de las diferentes normativas de las Comunidades Autónomas. Es decir, se ha subsanado uno de los males, pero quedan otros dos pendientes de subsanar.

Lo que sí parece estar claro, es que en aplicación de la Sentencia del Tribunal de Justicia de la Unión Europea, que declara contraria al Derecho Comunitario la normativa estatal, todos los contribuyentes no residentes que si lo sean en un Estado miembro de la Comunidad europea, que hayan pagado en demasía el Impuesto sobre Sucesiones y Donaciones, haciendo uso de su derecho, podrán reclamar la devolución de la suma abonada ilegalmente. Que también podría ser extensible a los contribuyentes residentes en terceros países, si atendemos a la interpretación del Tribunal de Justicia de la Unión Europea. Habrá que esperar la reacción de la Administración cuando proceda a devolver lo indebidamente cobrado.

\title{
VII. EL DERECHO Y PROTECCIÓN A LA PROPIEDAD PRIVADA Y A LA HERENCIA EN EL CONTEXTO COMUNITARIO ACTUAL
}

\author{
Revista de Estudios Jurídicos n ${ }^{\circ}$ 15/2015 (Segunda Época) \\ ISSN 2340-5066. Universidad de Jaén (España) \\ Versión electrónica: rej.ujaen.es
}


La Constitución española recoge en su texto (art. 33) como derechos la propiedad privada y la herencia, reconociendo su función social y estableciendo la posibilidad de privación de los mismos siempre que se deba por motivos de utilidad pública o interés social y, necesario para el provecho general, con arreglo a la ley. Si bien, la propiedad privada y la herencia no forman parte de los derechos fundamentales, por quedar incluidos en el Capítulo Segundo del Título Primero, relativo de los derechos y libertades de los ciudadanos, reconocidos como derechos económicos y sociales, si que tiene una gran trascendencia como base de nuestro sistema económico en los preceptos que le ofrece la Constitución ${ }^{45}$.

El concepto de propiedad ha sido uno de los derechos que más cambios ha sufrido en la historia, con una gran evolución desde la concepción absoluta de propiedad conocida por los romanos, hasta llegar a entenderla con una mayor implicación social. En efecto, la propiedad se considera como un hecho social en referencia al Estado social y democrático de Derecho que es proclamado por nuestra Constitución española de 1978 en su artículo primero, lo que conlleva necesariamente, que la configuración de cualquier derecho deberá realizarse de forma igualitaria y justa, cuando confluyan intereses que sean merecedores de una mayor tutela.

Esta concepción esencial constitucional del derecho a la propiedad privada no deja exclusividad a la subjetividad del derecho ni a la utilidad para los derechos individuales, sino que también, la hace extensible a la inclusión necesaria referente a la función social, en atención a los intereses de la comunidad, entendida, no como límite al ejercicio personal de la misma, sino que debe considerarse como sector que se integra en el mismo derecho. Por tanto, utilidad individual y función social, es lo esencial y, representan la configuración del derecho de propiedad sobre cada tipo de bienes, haciendo flexible con ello, la reserva de ley y demarcando su contenido, en virtud de la función social ${ }^{46}$.

Con otro alcance de gran importancia en la definición de la propiedad, la Constitución española de 1978 preceptúa en su artículo 128.1 como elemento clave, que cualquier tipo de patrimonio dentro del Estado y sea cual fuere su condición estará supeditada al interés general de todos los españoles. En todo caso, la incorporación de esa dimensión social a la institución de la propiedad privada no puede afectar ni mucho

\footnotetext{
${ }^{45}$ Dentro del texto constitucional, además del "art. 33 C.E. donde se reconoce el derecho a la propiedad privada y a la herencia, otros preceptos, como el art. 38 C.E. establece el principio de libertad de empresa en el ámbito de la economía de mercado, mientras que el art. 128 C.E. dispone la subordinación de toda la riqueza del país al interés general".

${ }^{46}$ STC 37/1987, de 26 de marzo (FJ 2), aduce el Tribunal Constitucional, que desde la perspectiva constitucional las exigencias sociales incorporadas al derecho de propiedad privada la transforman en una institución para retribuir las necesidades colectivas, por cuanto las mismas, responden a principios establecidos en la propia Constitución. Cabe mencionar, que el art. 128.1 CE somete íntegra la riqueza del Estado al interés general, mientras que el art. 40 obliga a todos los poderes públicos realizar las condiciones oportunas que favorezcan el progreso económico y social.
} 
menos anular el contenido individual de este derecho como institución jurídica. Pues de este modo, si quedase sometido a limitaciones que lo hicieran irrealizable, se desbordaría el contenido esencial del mismo, haciendo el derecho más vulnerable para su protección.

Asimismo, el artículo 348 del Código $\mathrm{Civil}^{47}$, quien ha recibido numerosas críticas, se muestra neutro al expresar que no deben existir más limitaciones que las que establece la ley, con lo cual, está habilitando al legislador para llevar a cabo un concepto más tolerante de la propiedad y hacerla más adecuada con las necesidades sociales en la configuración del derecho, dado que lo sustancial de la propiedad es su facilidad para adecuarse a las distintas situaciones o propuestas que puedan ofrecerse para el logro de la armonía social, pasando de ser un derecho individual a ser una institución jurídica objetiva limitada, en virtud de la configuración que exija la ley de acuerdo con las circunstancias y necesidades sociales, que pueden darse como es la expropiación forzosa.

No obstante, si la Constitución ha calificado la propiedad de privada, sin dejar de reconocer su función social, habrá que tener en cuenta, que este reconocimiento le faculta para estar en mayor medida a favor de la utilidad del contribuyente que de la Hacienda Pública, puesto que la propiedad del contribuyente no puede pertenecer más al servicio público que al privado ${ }^{48}$.

Con todo, cabe señalar además, la existencia de cuantiosos preceptos que hacen referencia a derechos e instituciones necesarios para configurar el modelo de propiedad privada consagrados en la formulación constitucional, entre tales preceptos figura el art. 31.1 CE al proclamar un sistema tributario justo e igualitario que en ningún caso tendrá alcance confiscatorio ${ }^{49}$. Desde esta perspectiva, que es la adoptada constitucionalmente, se desprende que la definición de la propiedad privada incorpora y cumple una función social y, del mismo modo, el Derecho Tributario efectúa una función redistributiva de la riqueza en nuestro Estado social y democrático de Derecho ${ }^{50}$.

Ahora bien, resulta necesario subrayar que, aún teniendo el Sistema tributario potestad para determinar la afectación de la carga tributaria a la propiedad privada, sus figuras no podrán incidir sobre la misma de forma que dejen vacío de contenido a tal derecho. Es decir, los tributos tienen facultad para afectar a la propiedad privada pero no pueden vulnerar los derechos constitucionales de las personas, que se encuentran

\footnotetext{
${ }^{47}$ DE LOS MOZOS Y DE LOS MOZOS, J.L., El derecho de propiedad, Crisis y retorno a la tradición jurídica, Editoriales de Derecho Reunidas, Edersa, Madrid, 1993, p. 232.

${ }^{48}$ GARCÍA COSTA, F.M., "El derecho de propiedad en la Constitución española de 1978”, Criterio jurídico, n. 7/2007, pp. 291 y 292.

${ }^{49}$ En materia de sucesiones y donaciones al respecto véase LÓPEZ ESPADAFOR, C.M., "Reflexiones sobre no confiscatoriedad e Impuesto sobre Sucesiones y Donaciones”, Quincena fiscal, n. 4/2012, p. 15.

${ }^{50}$ LÓPEZ ESPADAFOR, C.M., "La difícil interpretación del derecho de propiedad como límite en materia impositiva”, Crónica tributaria, n. 145/2012, pp. 155 y 156.
} 
preferentemente en el derecho a la propiedad privada y a la riqueza de los contribuyentes, mediante impuestos abusivos.

Desde esta óptica, los impuestos deben erigir la financiación de los bienes comunes de los contribuyentes, permitiendo la existencia de una mayor igualdad de oportunidades entre sus riquezas y necesidades, para lograr el pleno ejercicio de sus derechos económicos y sociales. Es decir, los tributos deben contribuir a hacer realidad los principios de justicia e igualdad, a través de las aportaciones de los ciudadanos, que es lo que conocemos como la función redistributiva de los impuestos.

\section{El derecho a la propiedad privada y su proyección en el ámbito tributario}

El Ordenamiento jurídico tributario debe inspirarse forzosamente en los principios materiales de justicia tributaria, contenidos en el art. 31.1 de la CE, que establece el deber de contribuir desde la capacidad económica de los sujetos, atendiendo a las medidas de igualdad y progresividad, como principios que inspiran al mismo, sin que en ningún caso pueda tener alcance confiscatorio. Por otra parte, la regulación de la propiedad privada contenida en el art. $33 \mathrm{CE}^{51}$, contempla un reconocimiento de libertad en el espacio económico, asegurando a los ciudadanos la protección y disfrute de sus bienes, para después facultar la privación por motivos de utilidad pública o interés social, lo cual refleja las exigencias de justicia social para hacer efectivo el principio constitucional de igualdad.

Ciertamente, desde cualquier enfoque, el fin de los tributos debe responder al bien común, por cuanto la aportación de los contribuyentes deberá destinarse a objetivos socialmente provechosos. Parece, pues, que de manera notable los ingresos y gastos están relacionados con la idea de justicia tributaria porque concurre un canje entre los mismos. Entonces, la tributación instituye un proyecto de justicia por cuanto aparece manifestado como reivindicación de justicia de los tributos y por ende del sistema tributario justo, al exigir que parte de la fortuna de los contribuyentes sean destinados a los gastos lícitos y necesarios, con el objetivo de atender al bien general social, para aproximarse desde la razonabilidad a los principios constitucionales que constituyen los criterios de reparto de la carga tributaria ${ }^{52}$.

Del reconocimiento constitucional en cuanto a la vertiente social del derecho de propiedad, se desprenden dos clausulas que operan ante la posesión y adquisición de la propiedad, derivándose de la función social el principio de igualdad que debe actuar ante la propiedad ya adquirida, mientras que en la función de accesibilidad a la

\footnotetext{
${ }^{51}$ LÓPEZ ESPADAFOR, C.M., "La contemplación del derecho de propiedad en el Derecho originario de la Unión Europea y su proyección en materia tributaria”, La Ley Unión Europea, n. 3/2013, p. 41.

${ }^{52}$ MASBERNAT, P., “Justicia y sistema tributario, Una mirada desde la perspectiva inglesa”, Díkaion, año 28, vol. 23, n. 1/2014, p. 146.
} 
propiedad, será el principio de igualdad ante la adquisición de aquella propiedad que resulte necesaria para lograr el progreso de la comunidad humana. Accesibilidad que se convierte en el compromiso para los poderes públicos de disponer de forma adecuada y equitativa la propiedad, para la consecución del bienestar general ${ }^{53}$.

Desde esta perspectiva, el deber de tributación debe configurarse como una manifestación de la función social que satisfaga el derecho a la propiedad privada, pero en todo caso, con sujeción al límite que le impone el principio de no confiscatoriedad ${ }^{54}$, dado que la tributación siempre deberá respetar los fundamentos económicos que lo sustentan. Por ello, aunque es indiscutible que la imposición actúa e incide sobre el derecho a la propiedad privada, no puede decirse que dificulte el desarrollo de un sistema tributario justo al encontrarse en espacios diferentes de actuación y, en caso de colisión de principios entre ambas instituciones amparadas por la Constitución ${ }^{55}$, deberá actuar la prohibición de alcance confiscatorio que limita los tributos, como garantía y respeto del derecho a la propiedad privada en materia tributaria, evitando así, las posibles interpretaciones que puedan darse de la propiedad privada en esta materia impositiva.

De acuerdo con esta tesitura, en la configuración del deber de contribuir, toca precisar que la prohibición de confiscatoriedad puede fortalecer aunque indirectamente, a los derechos consagrados en la Constitución como es el derecho a la propiedad privada, a la herencia y a la libertad, aumentando aún más el sentido de protección y garantía sobre los mismos. No obstante, la afectación que el Sistema tributario pueda injerir sobre el derecho a la propiedad privada, no podrá ser de forma que deje falta de contenido la propiedad del contribuyente, pagando más impuestos de lo que realmente puedan valer sus bienes. Es decir, que no se oprima la propiedad privada con excesivos impuestos o tributos.

Es grandemente reconocido por la doctrina, que el principio de no confiscatoriedad surge como una exigencia, en su acción como límite a la tributación, que se deduce de la garantía constitucional de la propiedad privada. Por ello, se atribuye por medio del sistema tributario la vinculación de la limitación de confiscación con atención al derecho a la propiedad privada. Esto es así, porque la restricción de confiscatoriedad es la pretensión de no acabar la riqueza imponible del contribuyente por la imposición de los tributos, para que se constituya permitida.

En efecto, es significativo destacar que el reconocimiento constitucional del deber de contribuir al sostenimiento de los gastos públicos, permite conciliar el requerimiento de

\footnotetext{
${ }^{53}$ REY MARTINEZ, F., “El devaluado derecho de propiedad privada”, Persona y derecho, Revista de fundamentación de las Instituciones Jurídicas y Derechos Humanos, n. 55/2006, p. 976.

54 AGULLÓ AGÜERO, A., "Una reflexión en torno a la prohibición de confiscatoriedad del sistema tributario”, Revista española de Derecho Financiero, Civitas, n. 36/1982, p. 561.

${ }^{55}$ LÓPEZ ESPADAFOR, C.M., La no confiscatoriedad en la imposición sobre el consumo, Publicaciones del Real Colegio de España, Bolonia, 2008, pp. 33 y 58.
}

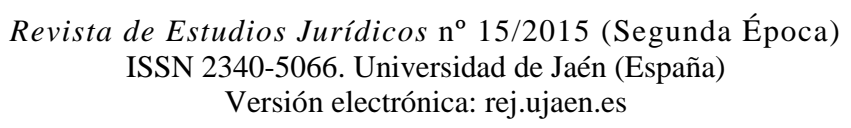


tributos con la garantía de propiedad, ya sea frente a privaciones de los bienes, con la finalidad de asegurar el pago de los tributos, tanto impuestos, contribuciones o tasas. Ello, nos permite valorar, que ambos preceptos no se encuentran en conflicto, aunque tampoco desconectados, pero lo cierto es que existe una conexión entre el deber de contribuir y el derecho a la propiedad, estableciendo el primero en un límite al derecho de propiedad.

A este propósito, es oportuno recordar, que el principio de no confiscatoriedad nos permite evaluar la admisibilidad de la afectación mediante el sistema tributario a los bienes del contribuyente, para entender, si resulta legítima o, habrá que fijar el límite a partir del cual el tributo será desfigurado. Podría decirse, que el derecho tributario dispone que el gravamen del valor de un bien, que sea establecido menor del treinta y tres por ciento no violaría la propiedad y por tanto no serán confiscatorios. De esta forma, la restricción constitucional de confiscatoriedad supondrá un componente añadido para conseguir el ideal de justicia tributaria.

En este contexto, cabe expresar, que dentro de la disciplina comunitaria, el Tratado de la Unión Europea en su artículo 6.2 establece que la Unión respetará los principios de materia tributaria, a la propiedad privada y la libertad de empresa ${ }^{56}$, de acuerdo con las constituciones de los Estados miembros en consideración a la soberanía estatal, por constituir los principios básicos del ordenamiento comunitario, pasando a formar parte del Derecho europeo como principios generales, cuyo respeto garantiza el Tribunal de Justicia. De ello se desprende, que en ese reconocimiento de la disciplina jurídica europea se encuentra consagrado el Derecho a la propiedad privada al que afectarán las normas emanantes de las instituciones europeas que vayan dirigidas a la armonización fiscal, las cuales no podrán establecer un impuesto que resulte confiscatorio ${ }^{57}$.

\section{RECIENTE PRONUNCIAMIENTO DEL CONSTITUCIONAL CONTRA DISCRIMINACIÓN TERRITORIAL POR MOTIVO DE RESIDENCIA EN SUCESIONES}

\footnotetext{
${ }^{56}$ FALCÓN Y TELLA, R., "La tasa suplementaria en el sector de la leche y de los productos lácteos, Un impuesto confiscatorio y discriminatorio entre ganaderos”, Quincena fiscal, n. 17/1997, p. 6.

${ }^{57}$ Cfr. LÓPEZ ESPADAFOR, C.M., "La necesidad de concreción de los principios materiales de justicia tributaria en el Tratado de Funcionamiento de la Unión Europea”, Estudios financieros, Revista de contabilidad y tributación, Comentarios, casos prácticos, n. 361/2013, pp. 85-124. Los principios materiales de justicia tributaria manifestados en las constituciones europeas suelen coincidir en su contenido esencial, pero no se refleja en el Derecho originario de la Unión Europea una concreción expresa de los mismos, aunque de sus instituciones se deriva la titularidad de competencias a través de la armonización fiscal, lo que lleva a que no le sean indiferentes los principios de justicia tributaria. Véase LÓPEZ ESPADAFOR, C.M., "Prospettive contemporanee dell'aplicazione della legge tributaria nello spazio", Diritto e practica tributaria internazionale, n. 4/2014, pp. 1190-1195 y del mismo autor, "Carencias de la justicia tributaria en la Unión Europea”, Revista técnica tributaria, n. 103/2013, pp. 3340.
} 
Tal y como hemos advertido, más pronto que tarde, el Tribunal Constitucional debería manifestarse para poner límites ante la constitucionalidad de la potestad tributaria que gozan las Comunidades Autónomas sobre el Impuesto de Sucesiones y Donaciones, al instituir en su normativa diferencias de trato por motivo de residencia, excluyendo así a contribuyentes tributarios de las deducciones y bonificaciones sobre la cuota, sin que se haya dado cualquier justificación objetiva y razonable.

Al respecto, en los últimos meses hemos concurrido a dos importantes sentencias referidas al Impuesto sobre Sucesiones y Donaciones recaídas, una por el Tribunal de Justicia de la Unión Europea (TJUE C-127/12, de 3 de septiembre de 2014) y más recientemente, otra del Tribunal Constitucional (STC 60/2015, de 18 de marzo), con significativos resultados positivos en ambos casos, al haber obligado a cambiar la ordenación normativa interna del impuesto sobre los contribuyentes comunitarios y, al resarcimiento de los ingresos indebidamente pagados en la Comunidad Valenciana por los sujetos no residentes en ella.

En este sentido, la diferencia de trato basada en la residencia, entre los obligados al pago que se encontraban en igualdad de condiciones, presumía una desigualdad artificiosa e injustificada, lo que llevó al Tribunal Supremo a plantear una cuestión de inconstitucionalidad ante el Tribunal Constitucional, sobre la regulación de la Comunidad Valenciana por supuesta infracción de la Ley 13/1997, de 23 de diciembre, que ordena el Impuesto sobre Sucesiones y Donaciones, recogiendo en su artículo 12, bis, según redacción dada por la Ley 10/2006, de 26 de diciembre, por incumplimiento de los artículos constitucionales de igualdad ante la Ley consagrado en el art. 14 y ante la Ley tributaria art. 31.1, así como del art.139.1, estimando la misma, lo que ha producido la declaración de inconstitucionalidad de la norma citada por la STC 60/2015, de 18 de marzo, alegando el Tribunal que la residencia no debe por sí sola, convertirse en la razón del trato diferente.

Por consiguiente, esta diferencia de trato en la tributación de manera desproporcionada y desigual, ha llevado a la nulidad del precepto legal, por someter el goce de una bonificación tributaria a la residencia habitual en esta Comunidad, estimando el Tribunal Constitucional que el legislador autonómico realizó un criterio disconforme con un sistema tributario justo, al vulnerar el principio de igualdad. No obstante, habrá que tener presente, el alcance de esta declaración de inconstitucionalidad, dado que el legislador suprimió desde el 1 de enero de 2015 este requisito de residencia, dejando claro el Alto Tribunal al respecto, que la redacción afectada por el fallo entra dentro de estos límites y son de plena aplicación.

\section{CONCLusiones}

1. A la luz de la doctrina del Tribunal de Justicia de la Unión Europea, parece claro el abandono del Estado español por el Impuesto sobre Sucesiones y Donaciones que ha llevado a que este impuesto pueda ser anulado por las Comunidades Autónomas, 
cuando constituye un mecanismo fundamental para el gravamen de la riqueza individual del sujeto pasivo. En base a este razonamiento, convendría reflexionar también sobre las diferencias de trato y tributación internas a que son sometidos los contribuyentes españoles conforme a la Comunidad Autónoma donde residan dentro del territorio español. Es evidente, que en el ámbito de esta cesión, las Comunidades Autónomas amparadas en su autonomía financiera pueden gozar de una diversidad normativa, aprobando deducciones y bonificaciones propias, creando un beneficio fiscal que solo será aplicado a su territorio, únicamente para los residentes e inmuebles que estén situados dentro de su comunidad.

2. Sin embargo, la autonomía tributaria tiene unos límites estrictos, debe realizarse con arreglo al principio de coordinación entre la Hacienda del Estado con las Comunidades Autónomas, dispuesto en el artículo 156 de la Constitución española de 1978, de manera que las competencias normativas cedidas por el Estado sobre el Impuesto de Donaciones y Sucesiones tendrán que garantizar la igualdad en el cumplimiento del deber de contribuir de los ciudadanos en todo el territorio del Estado y de solidaridad entre todos los españoles, para evitar el fraccionamiento y competitividad entre Comunidades. No obstante, entendemos que el establecimiento de beneficios fiscales sin estar sometidos a ningún límite, puede llevar a la eliminación total del gravamen, lo que supone un demasía para lograr el objetivo de la realización de los principios de unidad, solidaridad e igualdad que informan la organización territorial del Estado, quedando gravemente expuestos por la competencia desleal y la diversidad normativa autonómica.

3. En efecto, de acuerdo con la doctrina del Tribunal de Justicia de la Unión Europea, no se pretende en modo alguno poner en cuestión el reparto de competencias entre el Estado y las Comunidades Autónomas en materia fiscal, ni tampoco examinar la normativa de cada Comunidad Autónoma, sino solamente está en discusión, el criterio de conexión previsto por la legislación española, al admitir la posibilidad de que se dé distinto tratamiento a los sujetos pasivos en función de su residencia, aun cuando se encuentren en una misma situación que pueda ser comparable, lo que es suficiente para admitir una restricción de la libre circulación de capitales.

4. Es conveniente, que las reducciones y bonificaciones que admite la Ley del Impuesto de Sucesiones y Donaciones ${ }^{58}$ junto con las autonómicas se adapten a un mismo criterio, con el ánimo de permitir el acceso de todos los ciudadanos residentes y no residentes, a las citadas reducciones, llevados por el respeto al principio de igualdad tributaria y a la libre circulación de capitales, dado que no existe motivo alguno, para impedir que los ciudadanos no residentes no puedan acceder al disfrute de las bonificaciones de la legislación autonómica.

\footnotetext{
${ }^{58}$ Cfr. ADAME MARTÍNEZ, F.D., Fiscalidad de la transmisión de empresas en el Impuesto sobre Sucesiones y Donaciones, Comares, Granada, 2008, pp. 154-162.
} 
5. En consecuencia, los contribuyentes residentes o no, que hubieran soportado la repercusión del Impuesto sobre Sucesiones y Donaciones, tributando acorde a la normativa estatal, sea cual fuere el momento del pago de su liquidación, tienen derecho a solicitar la devolución de lo ingresado más los intereses de retraso, sin tener que acudir a realizar expediente de responsabilidad patrimonial del Estado, dado que una limitación de esta responsabilidad patrimonial por parte de la Administración Pública no cabe en ningún estado de derecho.

6. Desde la observancia del Derecho comunitario como del autonómico, encontramos diferencias muy notables a la hora de aplicar el Impuesto sobre Sucesiones y Donaciones. Tanto es así, que en muchos países europeos no existe el Impuesto, mientras que se mantiene en los más importantes de la Unión Europea, como es Francia. La falta de armonización a nivel comunitario y estatal, lleva a privar de interés a la inversión en los lugares con un gravamen muy elevado, al igual, a que muchas familias no puedan aceptar la herencia porque vale más el importe a pagar que lo recibido. Es evidente, que una armonización radical, supondría que se viera afectada la autonomía de los gobiernos en su actuación económica. Pero la falta de armonización puede dar lugar a la supresión del Impuesto, por lo que sería ideal que se adoptara una satisfacción razonable sobre todo en España, que vendría por mantener el impuesto reduciendo su tarifa, para adaptarlo a su carácter censal necesario para la Hacienda nacional, consiguiendo la igualdad en el plano tributario para todos los contribuyentes.

7. Las principales consecuencias de este desorden, pueden llevar a que en las Comunidades Autónomas que eximen del Impuesto sobre Sucesiones y Donaciones a sus contribuyentes, reciban un desbordamiento de las donaciones inter vivos, ante el recelo de que pueda llegar la esperada armonización del impuesto en todo el territorio nacional.

8. En fin, dista de estar claro, que por parte del Gobierno y su ejecutivo, el Impuesto de Sucesiones y Donaciones entrará de lleno en la reforma integral tributaria que se viene anunciando para modernizar el sistema fiscal. El año 2015 sería el momento oportuno para impulsar la consolidación fiscal en este impuesto de sucesiones, eliminando las exenciones, reducciones y bonificaciones existentes, distintas en un territorio u otro. Pero el Gobierno ya ha anunciado, que esta reforma integral no será posible hasta año 2016, con lo cual, la armonización del impuesto en todo el territorio del Estado, para sostener un óptimo grado de centralización en la gestión tributaria, no será posible de momento.

9. Por otro lado, es un hecho que la Sentencia del Tribunal de Justicia de la Unión Europea, de 3 de septiembre de 2014, asunto C-127/12, Comisión Europea contra Reino de España, ha juzgado al Estado español, pidiéndole que adecue el Impuesto sobre Sucesiones y Donaciones a la normativa europea, erradicando las diferencias en el trato fiscal en cuanto a donaciones y sucesiones entre los beneficiaros residentes o no residentes en España. Es decir, que tanto fuera o dentro del territorio español, debe haber armonía en la tributación, así lo exige el principio constitucional de igualdad en materia tributaria, que inspira el Sistema tributario. Además, de igual manera, lo

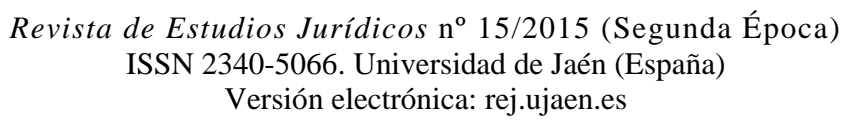


demanda el Tribunal de Justicia de la Unión Europea en su jurisprudencia, que al declarar la norma del Impuesto contraria al Derecho Comunitario y, siendo de obligado cumplimiento, dada su aplicabilidad directa y con efectos desde la misma fecha de su aprobación, llevará al Gobierno español a su regulación de conformidad con el art. 31.1 de la Constitución española de 1978, que preside la igualdad tributaria.

10. Entendemos, que el impuesto es necesario y también lo es su armonización, no se pretende que sea homogéneo en todo el territorio español, pero sí que mantenga unos cánones o mínimos que marquen la estela a seguir por las legislaciones, pues, si bien se sumergen en la autonomía financiera, lo hacen provocando un proceso de competencia fiscal discriminatoria entre los entes. Su contribución a la redistribución de la riqueza y su aportación como recurso financiero de las Comunidades Autónomas son argumentos suficientes que avalan su presencia en la actualidad. En este marco debe integrarse la reforma global del Impuesto sobre Sucesiones y Donaciones, que debe conformar una importante regulación mediante la aprobación de una nueva Ley, que lo adecue no solo a la legislación española, sino conciliada también con la legislación comunitaria.

11. Pues bien, como última hora y antes de la llegada de la reforma global tributaria prevista para 2016, el Gobierno ha tomado la iniciativa de modificar la Ley del Impuesto sobre Sucesiones y Donaciones para incorporar en la misma el juicio de la Sentencia del Tribunal de Justicia de la Unión Europea, de 3 de septiembre de 2014, asunto C-127/12, Comisión europea contra Reino de España, sobre el lugar de la residencia, y lo ha hecho, aprovechando la Ley 26/2014, de 27 de noviembre, por la que se modifican las leyes del IRPF, IRNR y otras normas tributarias, que en su Disposición final tercera recoge la modificación de la Disposición adicional segunda de la Ley 29/1987, de 18 de diciembre, del Impuesto sobre Sucesiones y Donaciones. Así, ha modificado la Ley 29/1987, de 18 de diciembre, del Impuesto sobre Sucesiones y Donaciones, dando nueva redacción a su Disposición adicional segunda, que permitirá la comparación de tratamiento en el impuesto en las posiciones discriminatorias marcadas por el Tribunal de Justicia de la Unión Europea, con vigencia desde el 1 de enero de 2015.

Con las normas propuestas, se ha intentado equiparar a los residentes españoles con los no residentes que lo sean en un Estado miembro de la Unión Europea o del Espacio Económico Europeo, ello lleva consigo, que también sufran las mismas desigualdades en la tributación del Impuesto sobre Sucesiones y Donaciones que los residentes en territorio español por aplicación de las distintas normativas que tienen las Comunidades Autónomas. Como se puede observar, es un paso adelante muy importante y satisfactorio, no obstante, quedan en el tintero matices que habrá que solucionarlos después. 